\title{
BUTAFOSFAN E CIANOCOBALAMINA: EFEITOS INDIRETOS NA RECUPERAÇÃO DA GLÂNDULA MAMÁRIA DE VACAS LEITEIRAS APÓS MASTITE CLÍNICA
}

\author{
TABELEÃO, Vinicius Coitinho ${ }^{1}$; \\ PEREIRA, Rubens Alves ${ }^{1}$; \\ PRIETSCH, Rafael da Fonseca ${ }^{1 ;}$ \\ FEIJÓ, Josiane Oliveira ${ }^{1}$; \\ BONDAN, Carlos ${ }^{3}$; \\ MATTEI, Patrícia ${ }^{1}$; \\ SCHMITT, Eduardo ${ }^{1}$; \\ DEL PINO, Francisco Augusto Burket ${ }^{1,2}$; \\ CORRÊA, Marcio Nunes ${ }^{1}$.
}

Recebido: 14/03/2016

Aceito: 28/09/2016

${ }^{1}$ Núcleo de Pesquisa, Ensino e Extensão em Pecuária, Departamento de Clínicas Veterinárias, Faculdade de Veterinária, Universidade Federal de Pelotas; ${ }^{2}$ Departamento de Bioquímica, CCQFA, Universidade Federal de Pelotas; ${ }^{3}$ Serviços de Análise de Rebanhos Leiteiros (SARLE), Faculdade de Agronomia e Medicina Veterinária, Universidade de Passo Fundo.

\section{RESUMO}

m vacas leiteiras, a recuperação da glândula mamária após a ocorrência de mastite é um processo que merece atenção especial. Sendo assim, o objetivo deste estudo foi avaliar o efeito da associação de butafosfan e cianocobalamina (BFC) na recuperação da glândula mamária de vacas leiteiras após o tratamento de mastite. Foram utilizadas 32 vacas da raça Holandês diagnosticadas com mastite clínica leve ( $n=18$, leite coagulado) e mastite clínica moderada ( $n=14$, leite coagulado e sinais clínicos). Dentro de cada categoria, os animais foram separados em dois grupos: Controle (CON, $n=15)$ que recebeu três aplicações por via intravenosa (IV) de placebo ( $\mathrm{NaCl} \mathrm{0,9 \% )} \mathrm{0,1} \mathrm{mL/kg} \mathrm{de} \mathrm{Peso} \mathrm{Vivo} \mathrm{(PV)} \mathrm{e}$ Grupo Tratado (GT/BFC, $n=17$ ) que recebeu três aplicações IV de $10 \mathrm{mg}$ de butafosfan $+5 \mu \mathrm{g}$ de cianocobalamina/kg de PV (Catosal ${ }^{\oplus} \mathrm{B}_{12}$, Bayer Animal Health) a cada 5 dias. Amostras de sangue foram coletadas após a ordenha, sendo $12 \mathrm{~h}$ antes e 12 e $36 \mathrm{~h}$ após a aplicação dos tratamentos, para análise de glicose, albumina, proteínas plasmáticas totais (PPT) e ácidos graxos não esterificados (AGNEs). Amostras individuais de leite foram coletadas $12 \mathrm{~h}$ antes, no momento da aplicação $(0 \mathrm{~h})$ e 12, 24 e $36 \mathrm{~h}$ após a realização dos tratamentos, para análise de proteína, caseínas totais, lactose, gordura, sólidos totais, ureia, $\mathrm{pH}$, crioscopia, densidade e contagem de células somáticas (CCS). A CCS no grupo GT/BFC foi menor $(p=0,02)$ após a terceira aplicação de BFC. O peso corporal, níveis de glicose, albumina, PPT, AGNEs e os parâmetros do leite não diferiram entre os grupos. A associação de butafosfan e cianocobalamina após o tratamento de mastite clínica pode contribuir para a redução da contagem de células somáticas do leite, tendo um papel importante no processo de recuperação da glândula mamária.

Palavras-chave: Células somáticas. Fósforo orgânico. Vitamina B12. 


\section{INTRODUÇÃO}

A mastite clínica é uma das enfermidades com maior ocorrência em vacas leiteiras, causando prejuízos aos sistemas de produção e à indústria de laticínios (SMITH., 2006). Esta doença pode ser originada a partir de traumas mecânicos (devido ao mau uso de máquinas e equipamentos), por agentes químicos ou como resultado de infecções causadas por microrganismos como bactérias, fungos e vírus (OVIEDO-BOYSO et al., 2007).

A mastite pode ocorrer na forma clínica, apresentando sinais de dor, edema, hiperemia e alterações macroscópicas das características do leite (SHIM et al., 2004). Além disso, de acordo com o grau de intensidade, pode ser classificada em leve, moderada ou grave (PARRA et al., 2009). Para o tratamento utiliza-se produtos tópicos (uso intramamário), sistêmicos (uso injetável) ou, ainda, uma combinação de ambos, variando de acordo com a intensidade do quadro clínico. Esses tratamentos têm demonstrado eficácia na cura dos animais com mastite clínica, contando para isso com diversos protocolos terapêuticos e princípios ativos (BRADLEY; GREEN, 2009; KLEEN et al., 2009; SCHUKKEN et al., 2011). Porém, o processo de recuperação da glândula mamária também depende do correto manejo e da total eliminação do agente causador (TREVISI et al., 2014), prevenindo uma recidiva ou até mesmo evitando a forma subclínica da enfermidade.

A mastite subclínica é diagnosticada principalmente pela contagem de células somáticas (CCS), que serve como indicador de saúde da glândula (BOUTET et al., 2004). As células somáticas são compostas por leucócitos e células epiteliais descamadas da glândula mamária (BOUTET et al., 2004; MEHRZAD et al., 2004; PAAPE et al., 2003) presentes em condições normais, porém durante a infecção aumentam as células leucocitárias. Os leucócitos são constituídos de linfócitos, macrófagos e neutrófilos, estes últimos representando mais de 90\% das células (KEHRLI; SHUSTER, 1994; SHARIF; MUHAMMAD, 2008; SHARMA et al., 2011) e são atraídos para o local da inflamação pelas citocinas próinflamatórias (BOUTET et al., 2004; OVIEDO-BOYSO et al., 2007; PAAPE et al., 2003).

Lesões na glândula mamária podem ter repercussão sistêmica no organismo, com alterações significativas que podem prejudicar outros tecidos e comprometer a fisiologia da vaca leiteira (MOYES et al., 2009). Além disso, as alterações metabólicas podem interferir na 
resposta imunológica celular, levando à diminuição na capacidade de resposta do sistema celular (MOYES et al., 2009; PARRA et al., 2009).

Outro sinal importante, tanto no início da doença quanto na recuperação da glândula mamária acometida por mastite, diz respeito às características do leite, já que podem surgir alterações nas concentrações de proteína, lactose e atividade enzimática, causando diminuição destes compostos (BRUCKMAIER et al., 2004; OGOLA et al., 2007), os quais, quando degradados, podem alterar as condições físicas do leite.

Diante dos desafios da produção leiteira, a associação de butafosfan e cianocobalamina (BFC) tem sido utilizada para minimizar a severidade do balanço energético negativo, reduzindo as concentrações de ácidos graxos não esterificados (AGNEs), prevenindo doenças como a cetose, e garantindo uma maior produção leiteira e de proteínas do leite (KREIPE et al., 2011; PEREIRA et al., 2013; ROLLIN et al., 2010). O butafosfan é uma fonte orgânica de fósforo, sua indicação convencional consiste no tratamento de desordens metabólicas e como um adjuvante na terapia de cálcio e magnésio (EMEA, 2000). No organismo o fósforo desempenha um importante papel no metabolismo hepático de carboidratos, pois todos os compostos intermediários da via gliconeogênica devem ser fosforilados. Assim, as taxas de gliconeogênese e glicogenólise podem ser reguladas pelas concentrações de fósforo (BERG et al., 2006). Já a cianocobalamina é uma forma sintética da vitamina B12 que atua como cofator da enzima methilmalonil-CoA mutase, responsável pela conversão do methilmalonilCoA em succinil-CoA, de tal modo que sua ação está relacionada à velocidade do ciclo de Krebs e da gliconeogênese (TAOKA et al., 1994). Estudos sobre os efeitos do BFC que possam interferir nas condições orgânicas de modo a potencializar a recuperação da glândula mamária acometida por mastite ainda não foram relatados.

Nesse sentido, o objetivo deste estudo foi avaliar o efeito do BFC na recuperação da glândula mamária de vacas leiteiras após o tratamento da mastite clínica. A hipótese é que a suplementação com BFC terá ação direta na glândula mamária, contribuindo para o processo de recuperação do órgão. 


\section{MATERIAL E MÉTODOS}

\section{Animais e manejos}

Para este estudo, foram utilizadas 32 vacas da raça Holandês, mantidas em sistema de semiconfinamento (concentrado e pastagem) de um rebanho comercial do extremo sul do Brasil $\left(32^{\circ} 16^{\prime} \mathrm{S}, 52^{\circ} 32^{\prime} \mathrm{O}\right)$. As vacas eram ordenhadas duas vezes ao dia ( $10 \mathrm{~h}$ e $22 \mathrm{~h}$ ) e recebiam uma dieta (Tabela 1) formulada com base nas exigências nutricionais (NRC, 2001) composta de concentrado e volumoso (azevém - Lolium multiflorium), fornecido entre as ordenhas. No

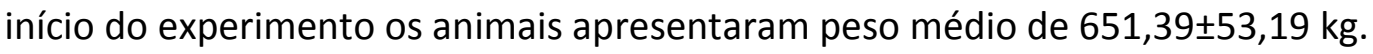

Tabela 1 - Ingredientes e composição nutricional da dieta fornecida às vacas após cada ordenha.

\begin{tabular}{ll}
\hline Alimentos & Quantidade $(\mathbf{K g})$ \\
\hline Azevém & Ad libitum \\
Pré-secado & 15,000 \\
Farelo de trigo & 1,500 \\
Farelo de soja & 2,400 \\
Farelo de arroz & 2,880 \\
Milho moído & 3,000 \\
Suplemento mineral & 0,110 \\
Sal & 0,002
\end{tabular}

Composição química da dieta fornecida no cocho

\begin{tabular}{ll}
\hline Matéria seca (\%) & 41,4 \\
$\operatorname{FDN}^{1}(\%)$ & 40,4 \\
$\operatorname{FDA}^{2}(\%)$ & 24,6 \\
Proteína (\%) & 10,6 \\
Extrato etéreo (\%) & 10,6 \\
Minerais totais (\%) & 7,83 \\
\hline
\end{tabular}

FDN $^{1}=$ Fibra Detergente Neutro; FDA ${ }^{2}$ = Fibra Detergente Ácida.

\section{Diagnóstico e terapia da mastite}

Através do teste da caneca de fundo escuro (PARRA et al., 2009), foram selecionados apenas animais com diagnóstico de mastite clínica, os quais foram categorizados em: mastite leve ausência de sinais clínicos, mas com presença de grumos, os animais desta categoria foram 
tratados com uma infusão intramamária contendo tetraciclina $(200 \mathrm{mg}$ ), neomicina (250 mg), bacitracina (2000 UI) e prednisolona (10 mg) (Mastijet Forte ${ }^{\circledR}$, MSD Saúde Animal, Brasil) no quarto acometido, 1 dose/dia, por três dias consecutivos, conforme protocolo adotado na propriedade onde foi realizado o estudo (Figura 1A); mastite moderada presença de sinais clínicos (dor e/ou edema e/ou hiperemia), além da presença de grumos em concentração superior a uma cruz, estes animais foram tratados com uma infusão intramamária com $88 \mathrm{mg}$ de sulfato de cefquinoma (Cobactan ${ }^{\circledR} \mathrm{VL}$, MSD Saúde Animal, Brasil) no quarto acometido, com 3 doses (uma a cada 12 h), associada ao sulfato de cefquinoma injetável (1 mg/kg PV) de ação sistêmica (Cobactan , MSD Saúde Animal, Brasil), com 2 doses (uma a cada 24 h), conforme protocolo adotado na propriedade (Figura 1B).

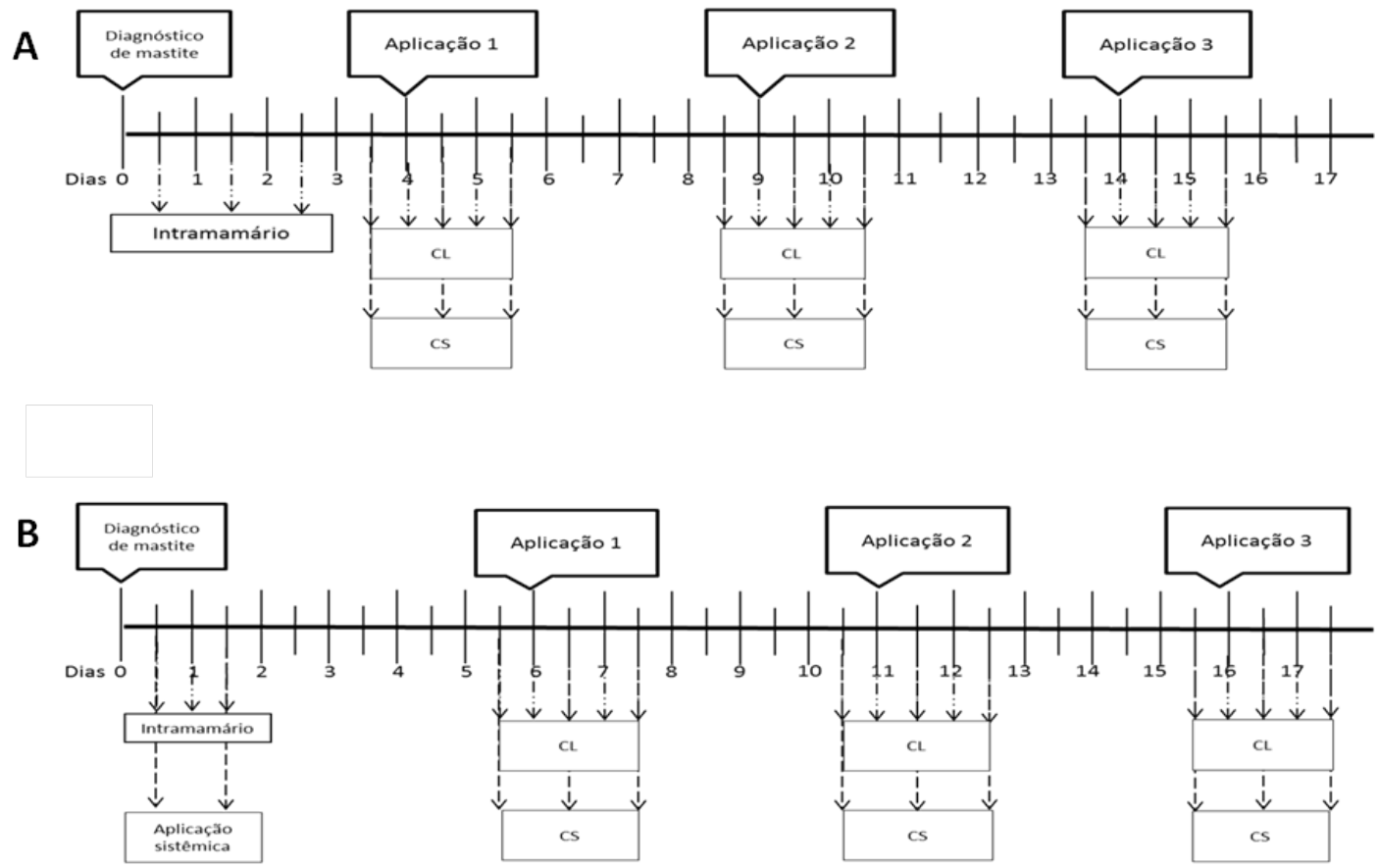

Figura $1-\mathrm{CL}=$ Coleta de leite. $\mathrm{CS}=$ Coleta de sangue. A) Protocolo de terapia antimicrobiana das vacas diagnosticadas com mastite leve. B) Protocolo de terapia antimicrobiana das vacas diagnosticadas com mastite moderada.

\section{Tratamentos e grupos experimentais}

As vacas diagnosticadas com mastite leve foram divididas em dois grupos: Grupo Controle $(\mathrm{CON}, \mathrm{n}=9)$ que recebeu três aplicações por via intravenosa (IV) de placebo $(\mathrm{NaCl}$ 0,9\%; 0,1 
$\mathrm{mL} / \mathrm{kg}$ PV), a cada cinco dias, a partir do 4,22 11,30 dias após a terapia antimicrobiana; Grupo Tratado (GT/BFC, n=9) que recebeu três aplicações IV de $10 \mathrm{mg}$ de butafosfan $+5 \mu \mathrm{g}$ de cianocobalamina/kg de PV (Catosal B $_{12}$, Bayer Animal Health, Brasil) a cada cinco dias, a partir do 4,22 $\pm 1,48$ dias após a terapia antimicrobiana. Da mesma forma, as vacas com mastite moderada foram divididas em dois grupos: Grupo Controle (CON, $n=6)$ que recebeu três aplicações IV de placebo ( $\mathrm{NaCl}$ 0,9\%; 0,1 mL/kg de PV), a cada cinco dias, a partir do 6,29 7,61 dias após a terapia antimicrobiana; Grupo Tratado (GT/BFC, $n=8$ ) que recebeu três aplicações IV de $10 \mathrm{mg}$ de butafosfan $+5 \mu \mathrm{g}$ de cianocobalamina/kg de PV (Catosal ${ }^{\circledR} \mathrm{B}_{12}$,

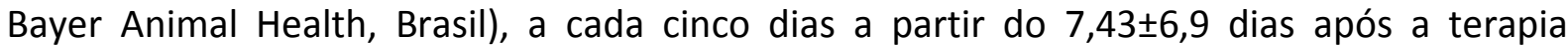
antimicrobiana.

Os animais foram acompanhados com inspeção da glândula mamária, além dos testes de diagnóstico de mastite clínica, a fim de monitorar os casos de reinfecção.

\section{Coletas de sangue}

As amostras de sangue foram coletadas por punção do complexo arterio-venoso coccígeo, após cada ordenha, sendo 12 horas antes e 12 e 36 horas após a administração de BFC e placebo (Figura 1). Em seguida foram armazenadas em dois tubos: um contendo anticoagulante (EDTA 10\%) e antiglicolítico (KF 12\%) e outro sem nenhuma solução. Ambos os tubos foram centrifugados a $1800 \times \mathrm{g}$ por 15 minutos e congelados a $-20^{\circ} \mathrm{C}$, ou resfriados a $4{ }^{\circ} \mathrm{C}$ para posteriores análises bioquímicas.

\section{Análises Bioquímicas}

As análises de glicose, albumina, proteínas plasmáticas totais (PPT) foram realizadas com kits colorimétricos e quantificadas em espectrofotômetro (CELM SB $190^{\circ}$, Brasil). Os reagentes foram manipulados conforme instruções do fabricante (Labtest ${ }^{\oplus}$ Diagnóstica S. A., Brasil). As análises de ácidos graxos não esterificados (AGNEs) foram realizadas com um kit comercial (Wako NEFA-HR, Wako Chemicals, EUA ${ }^{\circledR}$ ), conforme técnica padronizada por Ballou et al. (2009). Os coeficientes de variação foram inferiores a $10 \%$ em todos os ensaios. 


\section{Composição do leite}

As amostras de leite (amostragem da ordenha completa) foram coletadas nos períodos 12 horas antes e 0, 12, 24 e 36 horas depois em relação a cada aplicação de BFC e placebo (Figura 1), sendo posteriormente acondicionadas em frascos de polietileno, contendo conservante bronopol (2-bromo-2-nitropropano-1,3-diol), para depois serem analisadas por um sistema Delta Instruments ${ }^{\oplus}$. As análises de proteína, caseínas totais, lactose, gordura, sólidos totais, ureia, crioscopia, densidade e pH foram realizadas através do LactoScop FT 10 (série FT426601) que faz a mensuração por infravermelho. A CCS foi determinada através da metodologia de citometria de fluxo pelo equipamento SomatoScop CA3A5 (série SO421601).

\section{Análise estatística}

Os dados foram analisados tendo os animais como unidades experimentais. Todas as variáveis passaram pelo teste de normalidade Shapiro-Wilk $(p>0,90)$, pelo procedimento de UNIVARIATE. A comparação foi realizada através do MIXEDMODEL e a aproximação para determinação dos graus de liberdade pelo Satterthwaite para efeitos fixos. As análises metabólicas de glicose, albumina, PPT e AGNEs, além do peso corporal e os parâmetros do leite (proteína, caseínas totais, lactose, gordura, sólidos totais, ureia, crioscopia, densidade, $\mathrm{pH}$ e CCS) foram comparadas entre os tipos de mastite, tratamentos, bem como o momento da coleta e interações entre eles (LITTELL et al., 1998), por análise de variância com medidas repetidas. A estrutura de covariância simétrica composta forneceu o melhor ajuste para as análises de acordo com o critério de informação de Akaike. Além disso, o animal foi considerado como efeito aleatório dentro dos tratamentos e as coletas como medidas repetidas. Os resultados são apresentados como médias \pm erro padrão da média (EPM). Todas as análises estatísticas foram realizadas com o software SAS (SAS Institute Inc., Cary, NC, USA). Diferenças consideradas significativas continham $p \leq 0,05$.

\section{RESULTADOS E DISCUSSÃO}

As análises comparativas entre os graus de mastite, leve e moderada, não demonstraram interação $(p>0,05)$ entre si, nem interação delas com a administração de BFC feita durante a recuperação da glândula mamária em nenhum dos parâmetros analisados. Portanto, os 
dados foram agrupados para que as análises comparativas entre as médias fossem realizadas de acordo com a suplementação de BFC, sem considerar o grau de mastite.

A CCS média (Figura 2) no grupo GT/BFC (373.760 \pm 180.610 células $/ \mathrm{mL})$ foi menor $(p=0,02)$ após a terceira aplicação de BFC, quando comparado com o grupo CON (1.112.630 405.810 células/mL). O peso corporal dos animais do grupo GT/BFC $(648,82 \pm 16,62 \mathrm{~kg}$ de PV) não diferiu ( $p>0,05)$ do grupo CON $(621,17 \pm 16,62$ kg de PV), assim como não houve interação entre grupo e tempo $(p>0,05)$. Todos os animais perderam peso ao longo do estudo $(p<0,05)$.

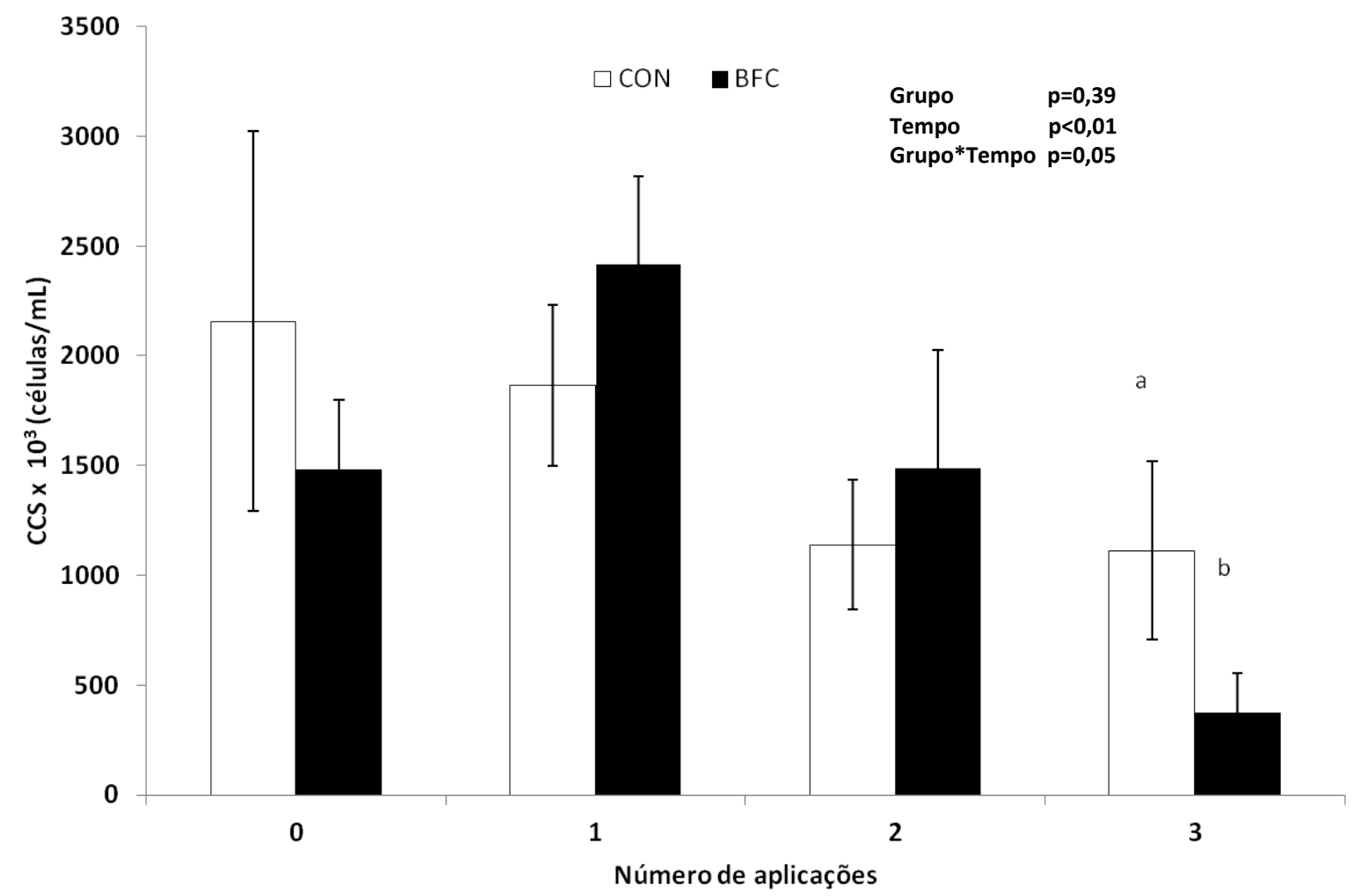

Figura 2 - Contagem (células $/ \mathrm{mL}$ ) de CCS (contagem de células somáticas) de vacas suplementadas com placebo (grupo CON, $\mathrm{n}=15$ ) ou com $10 \mathrm{mg}$ de butafosfan $+5 \mu \mathrm{g}$ de cianocobalamina/kg de PV (grupo GT/BFC, $n=17)$.

As concentrações de glicose, albumina, PPT e AGNEs (Tabela 2 ) não diferiram $(p>0,05)$ entre os grupos e suas interações $(p>0,05)$, embora tenha havido variação $(p<0,05)$ ao longo do tempo. O mesmo ocorreu com os parâmetros químicos do leite (proteína, lactose, gordura, caseínas totais, ureia, sólidos totais e pH) (Tabela 3) e com a densidade e a crioscopia (Tabela 4), que não diferiram $(p>0,05)$ entre os grupos e nem as interações entre o grupo e tempo. 
Tabela 2 - Concentração plasmática de glicose (mg/dL), albumina (g/L), PPT (mg/dL) e AGNEs (mmol/L) de vacas suplementadas com placebo (grupo $\mathrm{CON}, \mathrm{n}=15$ ) ou com $10 \mathrm{mg}$ de butafosfan $+5 \mu \mathrm{g}$ de cianocobalamina/kg de PV (grupo GT/BFC, $n=17$ ).

\begin{tabular}{llllll}
\hline Parâmetros $^{1}$ & Grupos & & \multicolumn{3}{l}{ Medidas repetidas (Valor de $\mathrm{p}$ ) } \\
& CON & GT/BFC & Grupo & Tempo & Grupo*Tem ${ }^{3}$ \\
\hline Glicose $(\mathrm{mg} / \mathrm{dL})$ & $47,52 \pm 0,97$ & $48,57 \pm 0,87$ & 0,42 & $<0,01$ & 0,72 \\
Albumina $(\mathrm{g} / \mathrm{L})$ & $2,82 \pm 0,06$ & $2,82 \pm 0,06$ & 0,90 & 0,21 & 0,97 \\
PPT $(\mathrm{mg} / \mathrm{dL})$ & $8,38 \pm 0,19$ & $8,40 \pm 0,18$ & 0,96 & 0,05 & 0,38 \\
AGNEs $(\mathrm{mmol} / \mathrm{L})$ & $0,322 \pm 0,01$ & $0,326 \pm 0,01$ & 0,94 & 0,04 & 0,92 \\
\hline
\end{tabular}

PPT = Proteínas Plasmáticas Totais; AGNEs = Ácidos Graxos Não Esterificados.

${ }^{1}$ Concentrações plasmáticas de glicose, albumina, PPT e AGNEs durante o período de recuperação da glândula mamária;

${ }^{2}$ Os grupos foram compostos por três aplicações a cada cinco dias, após a terapia antimicrobiana, nos grupos CON e GT/BFC, respectivamente. CON = Placebo $(\mathrm{NaCl}$ 0,9\%; 0,1 mL/kg de PV); GT/BFC = Grupo Tratado (10 mg butafosfan $+5 \mu$ g cianocobalamina/kg de PV em cada aplicação, Catosal $\left.{ }^{\circledR} \mathrm{B}_{12}{ }^{\circ}\right) ;$

${ }^{3}$ Análises de medidas repetidas e interação entre grupo e tempo; letras distintas na mesma linha indicam diferença entre os grupos $(p<0,05)$.

Tabela 3 - Média da concentração (\%) de lactose, proteína, caseínas totais, ureia, sólidos totais e pH de vacas suplementadas com placebo (grupo $\mathrm{CON}, \mathrm{n}=15$ ) ou com $10 \mathrm{mg}$ de butafosfan $+5 \mu \mathrm{g}$ de cianocobalamina/kg de PV (grupo GT/BFC, $n=17$ ).

\begin{tabular}{llllll}
\hline Parâmetros $^{1}$ & Grupos & & \multicolumn{3}{c}{ Medidas Repetidas (valor de p) } \\
& CON & GT/BFC & Grupos & Tempo & Grupo*Tem $^{3}$ \\
\hline Lactose & $3,96 \pm 0,100$ & $3,89 \pm 0,097$ & 0,64 & 0,34 & 0,84 \\
Proteína & $3,26 \pm 0,099$ & $3,27 \pm 0,098$ & 0,94 & $<0,01$ & 0,48 \\
Gordura & $3,28 \pm 0,16$ & $2,98 \pm 0,16$ & 0,32 & 0,02 & 0,23 \\
CT & $2,47 \pm 0,08$ & $2,48 \pm 0,07$ & 0,92 & $<0,01$ & 0,39 \\
Ureia & $16,80 \pm 0,81$ & $16,59 \pm 0,079$ & 0,86 & $<0,01$ & 0,83 \\
ST & $11,57 \pm 0,024$ & $11,34 \pm 0,24$ & 0,51 & 0,04 & 0,23 \\
pH & $6,50 \pm 0,021$ & $6,50 \pm 0,021$ & 0,88 & $<0,01$ & 0,38 \\
\hline
\end{tabular}

CT = Caseínas Totais; $\mathbf{S T}$ = Sólidos Totais.

${ }^{1}$ Concentrações (\%) de lactose, proteína, caseínas totais, ureia, sólidos totais e $\mathrm{pH}$ durante o período de recuperação da glândula mamária;

${ }^{2}$ Os grupos foram compostos por três aplicações a cada cinco dias, após a terapia antimicrobiana, nos grupos CON e GT/BFC, respectivamente. $\mathbf{C O N}=$ Placebo $(\mathrm{NaCl} 0,9 \% ; 0,1 \mathrm{~mL} / \mathrm{kg}$ de PV); GT/BFC = Grupo Tratado $(10 \mathrm{mg}$ butafosfan $+5 \mu \mathrm{g}$ cianocobalamina/kg de PV em cada aplicação, Catosal ${ }^{\bullet} \mathrm{B}_{12}{ }^{\circ}$ );

${ }^{3}$ Análises de medidas repetidas e interação entre grupo e tempo; letras distintas na mesma linha indicam diferença entre os grupos $(p<0,05)$. 
Tabela 4 - Parâmetros físicos do leite de crioscopia $\left({ }^{\circ} \mathrm{C}\right)$ e densidade $(\mathrm{g} / \mathrm{mL})$ de vacas suplementadas com placebo (grupo CON, $\mathrm{n}=15$ ) ou com $10 \mathrm{mg}$ de butafosfan $+5 \mu \mathrm{g}$ de cianocobalamina/kg de PV (grupo GT/BFC, $\mathrm{n}=17)$.

\begin{tabular}{llllll}
\hline Parâmetros $^{1}$ & Grupo $^{2}$ & & \multicolumn{2}{l}{ Medidas Repetidas (valor p) } \\
& CON & GT/BFC & Grupo & Tempo & Grupo*Tem $^{3}$ \\
\hline Crioscopia $\left({ }^{\circ} \mathrm{C}\right)$ & $-0,4753 \pm 0,01$ & $-0,4799 \pm 0,01$ & 0,54 & 0,15 & 0,92 \\
Densidade $(\mathrm{g} / \mathrm{mL})$ & $1028,61 \pm 0,44$ & $1028,20 \pm 0,45$ & 0,52 & 0,45 & 0,98
\end{tabular}

\footnotetext{
${ }^{1}$ Parâmetros de crioscopia $\left({ }^{\circ} \mathrm{C}\right)$ e densidade $(\mathrm{g} / \mathrm{mL})$ durante o período de recuperação da glândula mamária; ${ }^{2}$ Os grupos foram compostos por três aplicações a cada cinco dias, após a terapia antimicrobiana, nos grupos CON e GT/BFC respectivamente. $\mathbf{C O N}=$ Placebo $(\mathrm{NaCl}$ 0,9\%; 0,1 mL/kg de PV); GT/BFC = Grupo Tratado (10 mg butafosfan $+5 \mu$ g cianocobalamina/kg de PV em cada aplicação, Catosal $\left.{ }^{\circledR} \mathrm{B}_{12}{ }^{\circ}\right)$;

${ }^{3}$ Análises de medidas repetidas e interação entre grupo e tempo; letras distintas na mesma linha indicam diferença entre os grupos $(p<0,05)$.
}

Todos os tratamentos para as mastites leve e moderada foram eficazes na cura clínica dos animais, desta forma denotando que o diagnóstico empregado para classificar o grau da mastite, assim como o protocolo terapêutico para cada um dos diferentes graus utilizado foram eficientes, uma vez que não houve recidiva da doença.

Os animais do grupo GT/BFC apresentaram menor CCS no leite $(33,59 \%$ da CCS encontrada no grupo CON) após a terceira aplicação (Figura 2), o que indica uma maior aceleração na recuperação funcional do tecido mamário, além da resposta esperada pelas terapias. Esta resposta acentuada no grupo GT/BFC, pode ter ocorrido devido à disponibilidade do fósforo, contido na molécula de butafosfan (EMEA, 2000), servindo de substrato para a tirosina quinase, responsável por fosforilar as proteínas do citoesqueleto dos neutrófilos, permitindo a emissão de pseudopodes, necessários para a fagocitose (BERKOW; DODSON, 1990; MECONI et al., 2001; MEHRZAD et al., 2004), a proliferação, a diferenciação (MONFARDINI et al., 2002) e o prolongamento da vida (SWEENEY et al., 1998). Além disso, o fósforo suplementar recebido pelo grupo GT/BFC, pode ter auxiliado na fosforilação do inibidor kappa-B (IkB), possibilitando a translocação do fator de transcrição nuclear kappa-B (NF-KB) para dentro do núcleo, incrementando a síntese de citocinas, que por sua vez atraem mais leucócitos para o local da inflamação (BOULANGER et al., 2003; PAAPE et al., 2003), diminuindo assim a carga de microrganismos na glândula mamária e, consequentemente, a CCS do leite (Figura 2). 
Como estas reações demandam grande consumo de energia, a cianocobalamina, como cofator enzimático, pode ter contribuído para o aumento da neoglicogênese, assim como foi observado num estudo sobre o tecido hepático (KREIPE et al., 2011), embora as concentrações de glicose não tenham diferido entre os grupos. A glicose é fundamental para o sistema imune celular, por ser utilizada nas rotas de proliferação, sobrevivência e diferenciação das células fagocitárias (MOYES et al., 2009; PITHON-CURI et al., 2004), permitindo que os leucócitos sejam mais eficientes no processo de recuperação funcional da glândula mámaria.

De mesma forma, os AGNEs que são indicadores de equilíbrio energético do organismo, não diferiram entre os grupos. Os AGNEs já demonstraram efeito na diminuição da capacidade fagocitária in vitro, mas em concentrações três vezes maiores (BERTONI et al., 2008; SANDER et al., 2011) em relação as utilizadas no presente estudo. Ainda, altos níveis de AGNEs têm sido associados ao maior risco de mastite clínica, em especial no periparto (MELENDEZ et al., 2009), mas não no processo de recuperação da glândula mamária.

As concentrações plasmáticas de albumina não diferiram entre os grupos. Essa proteína é considerada preditora da resposta inflamatória de fase aguda (BERTONI et al., 2008), variando suas concentrações somente nos primeiros momentos do processo (MOYES et al., 2009), logo suas concentrações deveriam ser mantidas durante o período de recuperação da glândula mamária. Da mesma forma, as PPT não sofreram alteração com a suplementação, apesar de outros estudos mostrarem diminuição nas concentrações plasmáticas em vacas com mastite clínica, mas em comparação com vacas saudáveis, tendo ainda como consequência alterações nos componentes químicos do leite (PARRA et al., 2009).

As concentrações de lactose, gordura, proteína, caseínas totais, ureia e sólidos totais do leite, também não sofreram alterações durante o período de recuperação da glândula mamária, corroborando com os resultados de Furll et al. (2010), que também não encontraram alterações na composição química do leite após três aplicações de BFC. Nossos resultados podem estar associados ao mecanismo de controle de síntese dos constituintes do leite, visto que estes dispõem de uma complexa rede de genes e mediadores proteicos (BIONAZ; LOOR, 2011). Entretanto, um aumento nas concentrações protéicas foi constatado 
em outros estudos, mas com maior número de aplicações da associação (FURLL et al., 2010; PEREIRA et al., 2013).

Os resultados de crioscopia, densidade e pH do leite também não diferiram entre os grupos, o que pode ser atribuído ao fato de que as proteínas, mas principalmente a lactose, são higroscópicas (BOUTINAUD et al., 2008), impedindo a variação nas características físicas do leite, as quais são verificadas somente quando comparadas vacas saudáveis com vacas com mastite, devido ao aumento de permeabilidade causado pela inflamação da glândula mamária (BRUCKMAIER et al., 2004; OGOLA et al., 2007).

Nossos resultados mostraram que o butafosfan e a cianocobalamina podem ter agido diretamente na glândula mamária, pois os marcadores metabólicos que representam o status sistêmico permaneceram dentro dos padrões fisiológicos, demonstrando que o butafosfan e a cianocobalamina podem ter atuado nas rotas metabólicas que estavam em maior atividade no momento, ou seja, as da glândula mamária.

\section{CONCLUSÃO}

A associação de butafosfan e cianocobalamina após o tratamento de mastite clínica pode colaborar para a redução da contagem de células somáticas no leite, tendo um papel importante no processo de recuperação da glândula mamária.

\section{BUTAFOSFAN AND CYANOCOBALAMIN: INDIRECT EFFECTS ON THE RECOVERY OF THE MAMMARY GLAND OF DAIRY COWS AFTER CLINICAL MASTITIS}

\section{ABSTRACT}

I

$\mathrm{n}$ dairy cows, the recovery of the mammary gland after the occurrence of mastitis is a process that deserves special attention. Therefore, the aim of this study was to evaluate the effect of butafosfan and cyanocobalamin (BFC) association on the mammary gland recovery of dairy cows after treatment of mastitis. 32 Holstein cows with mild clinical mastitis ( $n=18$; coagulated milk) and moderate clinical mastitis ( $n=14$; coagulated milk and clinical signs) were used. Within each category, the animals were divided into two groups: control (CON, $\mathrm{n}=15)$ that received three placebo $(0.9 \% \mathrm{NaCl}, 0.1 \mathrm{ml} / \mathrm{kg} \mathrm{BW})$ applications IV and Treated Group (TG/BFC, $\mathrm{n}=17$ ) that received three applications IV of $10 \mathrm{mg}$ butafosfan + $5 \mu \mathrm{g}$ cyanocobalamin/kg BW (Catosal ${ }^{\circledR}$ B12, Bayer Animal Health), every 5 days. Blood 
samples were collected after milking $12 \mathrm{~h}$ before the treatment, $12 \mathrm{~h}$ and 36 hours after the treatment for the analysis of glucose, albumin, total plasma proteins (TPP) and nonesterified fatty acids (NEFA). Individual milk samples were collected $12 \mathrm{~h}$ before, at the moment of the application ( $0 \mathrm{~h}$ ) and 12, 24 and 36 hours after injection, for the analysis of protein, total casein, lactose, fat, total solids, urea, $\mathrm{pH}$, freezing point, density and somatic cell count (SCC). SCC in TG/BFC group was lower $(p=0.02)$ after the third dose of BFC. Body weight, glucose levels, albumin, TPP, NEFA and milk parameters did not differ among groups. The administration of butafosfan and cyanocobalamin, after treatment of clinical mastitis, can contribute to the reduction of milk somatic cell count having an important role in the recovery process of the mammary gland.

Keywords: Somatic cells. Organic phosphorus. Vitamin B12.

\section{BUTAFOSFAN Y CIANOCOBALAMINA: EFECTOS INDIRECTOS EN LA RECUPERACIÓN DE LA GLÁNDULA MAMARIA EN VACAS DE LECHE CON MASTITIS CLÍNICA}

\section{RESUMEN}

$\square$ n vacas lecheras, la recuperación de la glándula mamaria después de la aparición de mastitis es un proceso que merece una atención especial. Por consiguiente, el objetivo de este estudio fue evaluar el efecto de la asociación de butafosfan y cianocobalamina (BFC) en la recuperación de la glándula mamaria de vacas lecheras después del tratamiento para mastitis. Fueron utilizadas 32 vacas con mastitis clínica leve ( $n=18$; leche coagulada) o con mastitis clínica moderada ( $n=14$; leche coagulada y signos clínicos). Dentro de cada categoría, los animales fueron divididos en dos grupos: Control (CON, $n=15)$ que recibieron tres aplicaciones IV de placebo $(\mathrm{NaCl} 0,9 \%) 0,1 \mathrm{~mL} / \mathrm{kg}$ de peso corporal y Grupo Tratado (GT/BFC, $\mathrm{n}=17$ ) que recibieron tres aplicaciones IV de $10 \mathrm{mg}$ de butafosfan $+5 \mu \mathrm{g}$ de cianocobalamina/kg de peso corporal (Catosal ${ }^{\circledR} \mathrm{B}_{12}$, Bayer Animal Health), a cada 5 días. Las muestras de sangre se recogieron después del ordeño a -12, 12, y 36 horas en relación a la aplicación de los tratamientos, para análisis de glucosa, albúmina, proteínas plasmáticas totales (PPT) y ácidos grasos no esterificados (AGNEs). Muestras de leche individuales fueron tomadas a -12, 0, 12, 24 y 36 horas después de la inyección para el análisis de proteínas, caseína total, lactosa, grasa, sólidos totales, urea, $\mathrm{pH}$, punto de congelación, densidad y recuento de células somáticas (RCS). El RCS en el grupo GT/BFC fue inferior $(p=0,02)$ después de la tercera dosis de BFC. El peso corporal, glucosa, albúmina, PPT, AGNEs y parámetros de la leche no difirieron entre los grupos. Los resultados indican que el uso de la combinación de butafosfan y cianocobalamina después del tratamiento de mastitis clínica puede contribuir a la reducción del recuento de células somáticas de la leche, teniendo un papel importante en el proceso de recuperación de la glándula mamaria.

Palabras clave: Células somáticas. Fósforo orgánico. Vitamina B12. 


\section{REFERÊNCIAS}

BALLOU, M. A.; GOMES, R. C.; JUCHEM, S. O.; et al. Effects of dietary supplemental fish oil during the peripartum period on blood metabolites and hepatic fatty acid compositions and total triacylglycerol concentrations of multiparous Holstein cows. Journal of Dairy Science, vol. 92, p. 657-669, 2009.

BERG, J. M.; TYMOCZKO, J. L.; STRYER, L. Glycolysis and gluconeogenesis. In: BERG, J. M.; TYMOCZKO, J. L.; STRYER, L. (Eds.). Biochemistry. 6. ed. New York: W.H. Freeman and Co. p. 433-474, 2006.

BERKOW, R.; DODSON, R. Tyrosine-specific protein phosphorylation during activation of human neutrophil. Journal of The American Society of Hematology, vol. 75, p. 2445-2452, 1990.

BERTONI, G.; TREVISI, E.; HAN, X.; et al. Effects of inflammatory conditions on liver activity in puerperium period and consequences for performance in dairy cows. Journal Dairy Science, vol. 91, p. 3300-3310, 2008.

BIONAZ, M.; LOOR, J. J. Gene networks driving bovine mammary protein synthesis during the lactation cycle. Bioinformatics and Biology Insights, vol. 5, p. 83-98, 2011.

BOULANGER, D.; BUREAU, F.; MÉLOTTE, D.; et al. Increased Nuclear Factor kb Activity in Milk Cells of Mastitis-Affected Cows. Journal of Dairy Science, vol. 86, p. 1259-1267, 2003.

BOUTET, P.; BOULANGER, D.; GILLET, L.; et al. Delayed neutrophil apoptosis in bovin e subclinical mastitis. Journal Dairy Science, vol. 87, p. 4104-4114, 2004.

BOUTINAUD, M.; BEN CHEDLY, M. H.; DELAMAIRE, E.; et al. Milking and feed restriction regulate transcripts of mammary epithelial cells purified from milk. Journal Dairy Science, vol. 91, p. 988-998, 2008.

BRADLEY, A. J.; GREEN, M. J. Factors affecting cure when treating bovine clinical mastitis with cephalosporin-based intramammary preparations. Journal Dairy Science, vol. 92, p. 1941-1953, 2009.

BRUCKMAIER, R. M.; ONTSOUKA, C. E.; BLUM, J. W. Fractionized milk composition in dairy cows with subclinical mastitis. International Journal for Veterinary and Biomedical Science, vol. 49, p. 283-290, 2004.

EMEA - EUROPEAN AGENCY FOR THE EVALUATION OF MEDICINAL PRODUCTS. Veterinary Medicines and Information Technology Unit. London: EMEA/MRL/734/00 FINAL, p 1-2, 2000. 
FURLL, M.; DENIZ, A.; WESTPHAL, B.; et al. Effect of multiple intravenous injections of butaphosphan and cyanocobalamin on the metabolism of periparturient dairy cows. Journal Dairy Science, v. 93, p. 4155-4164, 2010.

KEHRLI, M. E.; SHUSTER, D. E. Factors affecting milk somatic cells and their role in health of the bovine mammary gland. Journal Dairy Science, vol. 77, p. 619-627, 1994.

KLEEN, J. L.; BARRETT, D. C.; COURCIER, E.; BIGGS, A. M. Comparison of two treatments for clinical mastitis using cefquinome (COBACTAN $\left.{ }^{\circledR}\right)$. In: BRITISH MASTITIS CONFERENCE, 2009, Stoneleigh Park. Proceedings. The University of Nottingham, 2009.

KREIPE, L.; DENIZ, A.; BRUCKMAIER, R. M.; et al. First report about the mode of action of combined butafosfan and cyanocobalamin on hepatic metabolism in nonketotic early lactating cows. Journal Dairy Science, vol. 94, p. 4904-4914, 2011.

LITTELL, R. C.; HENRY, P. R.; AMMERMAN, C. B. Statistical analysis of repeated measures data using SAS procedures. Journal of Animal Science, vol. 76, p. 1216-1231, 1998.

MECONI, S.; CAPO, C.; REMACLE-BONNET, M.; et al. Activation of protein tyrosine kinases by Coxiella burnetii: role in actin cytoskeleton reorganization and bacterial phagocytosis. Infection and Immunity, vol. 69, n. 4, p. 2520-2526, 2001.

MEHRZAD, J.; DUCHATEAU, L.; BURVENICH, C. Viability of milk neutrophils and severity of bovine coliform mastitis. Journal Dairy Science, vol. 87, p. 4150-4162, 2004.

MELENDEZ, P.; MARIN, M. P.; ROBLES, J.; et al. Relationship between serum nonesterified fatty acids at calving and the incidence of periparturient diseases in Holstein dairy cows. Theriogenology, vol. 72, p. 826-833, 2009.

MONFARDINI, E.; PAAPE, M. J.; WANG, Y.; et al. Evaluation of L-selectin expression and assessment of protein tyrosine phosphorylation in bovine polymorphonuclear neutrophil leukocytes around parturition. Veterinary Research, vol. 33, p. 271-281, 2002.

MOYES, K. M.; LARSEN, T.; FRIGGENS, N. C.; et al. Identification of potential markers in blood for the development of subclinical and clinical mastitis in dairy cattle at parturition and during early lactation. Journal Dairy Science, vol. 92, p. 5419-5428, 2009.

NRC - NATIONAL RESEARCH COUNCIL. Nutrient requirements of dairy cattle. 7. ed. Washington, 2001. 381p.

OGOLA, H.; SHITANDI, A.; NANUA, J. Effect of mastitis on raw milk compositional quality. Journal of Veterinary Science, vol. 8, p. 237-242, 2007. 
OVIEDO-BOYSO, J.; VALDEZ-ALARCON, J. J.; CAJERO-JUAREZ, M.; et al. Innate immune response of bovine mammary gland to pathogenic bacteria responsible for mastitis. Journal of Infection, vol. 54, p. 399-409, 2007.

PAAPE, M. J.; BANNERMAN, D. D.; ZHAO, X.; et al. The bovine neutrophil: Structure and function in blood and milk. Veterinary Research, vol. 34, p. 597-627, 2003.

PARRA, A. J. A.; ORTEGA, A. A. L.; MENDOZA, C. A.; et al. Efecto de la mastitis clínica y subclínica sobre la concentración plasmática de metabolitos, proteínas totales y albúmina en hembras bovinas. Zootecnia Tropical, vol. 27, n. 1, p. 57-63, 2009.

PEREIRA, R. A.; SILVEIRA, P. A.; MONTAGNER, P.; et al. Effect of butaphosphan and cyanocobalamin on postpartum metabolism and milk production in dairy cows. Animal, vol. 7, n. 7, p. 1143-1147, 2013.

PITHON-CURI, T. C.; DE MELO, M. P.; CURI, R. Glucose and glutamine utilization by rat lymphocytes, monocytes and neutrophils in culture: a comparative study. Cell Biochemistry and Function, vol. 22, p. 321-326, 2004.

ROLLIN, E.; BERGHAUS, R. D.; RAPNICKI, P.; et al. The effect of injectable butaphosphan and cyanocobalamin on postpartum serum beta-hydroxybutyrate, calcium, and phosphorus concentrations in dairy cattle. Journal Dairy Science, vol. 93, p. 978-987, 2010.

SANDER, A. K.; PIECHOTTA, M.; SCHLAMBERGER, G.; et al. Ex vivo phagocytic overall performance of neutrophilic granulocytes and the relation to plasma insulin-like growth factor-I concentrations in dairy cows during the transition period. Journal of Dairy Science, vol. 94, p. 1762-1771, 2011.

SCHUKKEN, Y. H.; BENNETT, G. J.; ZURAKOWSKI, M. J.; et al. Randomized clinical trial to evaluate the efficacy of a 5-day ceftiofur hydrochloride intramammary treatment on nonsevere gram-negative clinical mastitis. Journal Dairy Science, vol. 94, p. 6203-6215, 2011.

SHARIF, A.; MUHAMMAD, G. Somatic cell count as an indicator of udder health status under modern dairy production: a review. Pakistan Veterinary Journal, vol. 28, n. 4, p. 194-200, 2008.

SHARMA, N.; SINGH, N. K.; BHADWAL, M. S. Relationship of Somatic Cell Count and Mastitis: An Overview. Asian-Aust. Journal of Animal Science, vol. 24, p. 429-438, 2011.

SHIM, E. H.; SHANKS, R. D.; MORIN, D. E. Milk Loss and Treatment Costs Associated with Two Treatment Protocols for Clinical Mastitis in Dairy Cows. Journal Dairy Science, vol. 87, p. 2702-2708, 2004. 
SMITH, B. P. Medicina Interna de Grandes Animais. 3. ed. Barueri: Manole, 2006.

SWEENEY, J. F.; NGUYEN, P. K.; OMANN, G. M.; et al. Lipopolysaccharide Protects Polymorphonuclear Leukocytes from Apoptosis via Tyrosine Phosphorylation-Dependent Signal Transduction Pathways. Journal of Surgical Research, vol. 74, p. 64-70, 1998.

TAOKA, S.; PADMAKUMAR, R.; LAI, M.; LIU, H; et al. Inhibition of the human methylmalonylCoA mutase by various CoA esters. Journal of Biological Chemistry, vol. 269, p. 31630-31634, 1994.

TREVISI, E.; ZECCONI, A.; COGROSSI, S.; et al. Strategies for reduced antibiotic usage in dairy cattle farms. Research in Veterinary Science, vol. 96, p. 229-233, 2014. 